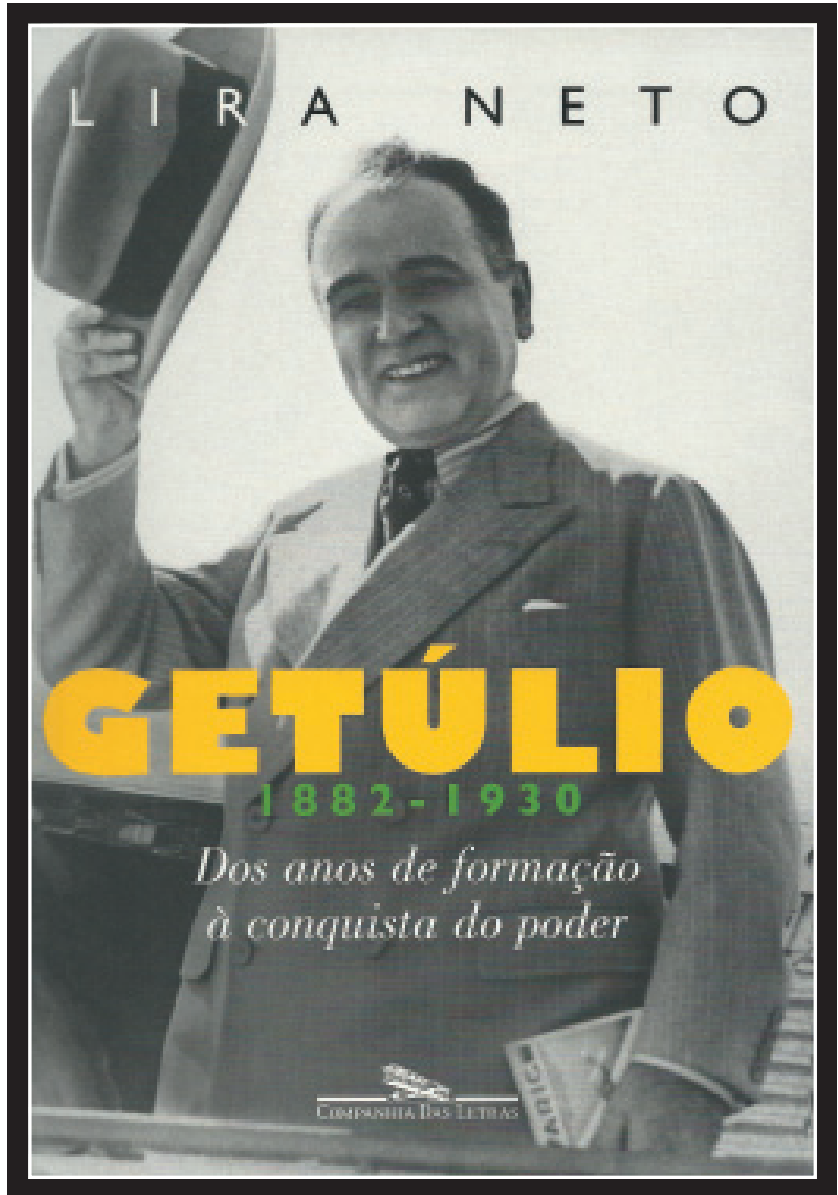

Getúlio, 1882-1930: dos anos de formação à conquista do poder, de Lira Neto. São Paulo: Companhia das Letras, 2012, 629p. 


\title{
Getúlio antes da Presidência visto por jornais e revistas
}

Getúlio before the presidency viewed by newspapers and magazines

\author{
Márcio Fernandes*
}

Quem olha de relance o volumoso livro que Lira Neto escreveu sobre o mais discutido presidente do Brasil pode pensar que se trata de uma obra cansativa, de consumo lento e, portanto, longo. Getúlio, 1882-1930: dos anos de formação à conquista do poder é exatamente o contrário, pois o autor, misto de jornalista e escritor, tem uma prosa de alta qualidade. E zela, tanto quanto possível, por completar sua prosa com o uso de imagens interessantes e, em muitas situações, raras - como uma do jovem Getúlio como estudante de direito, com vasta cabeleira e bigode, uma cena garimpada pelo autor junto ao acervo do fotógrafo Renato Parada. Quem pega o livro e começa sua leitura, tende a não desgrudar mais até que a mesma acabe. Getúlio, 1882-1930 é, com toda tranquilidade, um dos melhores lançamentos editoriais de 2012 e uma das partes mais interessantes pode ser descoberta lá nas folhas derradeiras, onde ficam o índice remissivo e os créditos das imagens.

É pelo índice que se pode ter uma visão mais acurada do quão importantes foram os jornais e revistas brasileiras da época retratada no livro, servindo de instrumentos para que o futuro mandatário da nação fosse construindo (ou sendo erigido do ponto de vista simbólico), sedimentando publicamente seu pensamento social e político, fosse apresentando ideias ou projetos ou, não raro, combatendo os opositores - enquanto sujeito que concedia entrevistas ou remetia

\footnotetext{
* Graduado em Comunicação Social - Habilitação Jornalismo pela Universidade Federal de Santa Maria (UFSM). Doutor em Comunicação e Cultura pela Universidade Federal do Rio de Janeiro (UFRJ), com doutoramento-sanduíche pela Universidade de Lisboa (UL). Professor adjunto do Departamento de Comunicação Social (Decs) e diretor de Comunicação Social da Universidade Estadual do Centro-Oeste (Unicentro). E-mail: marciorf@globo.com
} 
textos próprios ou na condição de personagem de reportagens ou ilustrações. Ou que podia ser objeto de escárnio ou louvor nas fotografias, charges e caricaturas que saíam a todo instante Brasil afora.

No final dos anos 1910, um Getúlio ainda pouco (ou quase nada) conhecido em âmbito nacional se embrenhou em uma acalorada discussão na Assembleia dos Representantes do Rio Grande do Sul (nome antigo para Assembleia Legislativa) sobre a construção, por parte do poder público estadual, do porto de Rio Grande, uma obra gigantesca para a época. Neto, na página 161 , conta que a polêmica serviu de inspiração para uma antológica charge do minúsculo jornal Bisturi (de Porto Alegre), na qual o RS era retratado como um ente que estava afundando rapidamente, por conta do elevado custo do empreendimento portuário.

Mas, enquanto o Bisturi é citado somente uma vez no livro, algo distinto ocorre com outros veículos da época. O Correio do Povo, também da capital gaúcha, era um deles. Na primeira das mais de 40 vezes em que serve de referência para o autor, uma edição de agosto de 1906 do periódico reporta que Getúlio, então estudante do quarto ano da Faculdade de Direito de Porto Alegre, havia co-assinado um manifesto dizendo que, naqueles instantes, os estudantes universitários da cidade estavam se sentindo "melindrados com sucessivas descortesias feitas pelo governo do estado" em relação à eventual participação deles nos festejos da recepção ao então presidente eleito do Brasil, Afonso Pena, em vias de chegar a Porto Alegre. Getúlio, aos 24 anos, começava uma carreira política que, não sendo meteórica (sobretudo para os padrões atuais), acabaria se tornando ímpar na história do país.

Com firmeza, Lira Neto conta que o episódio da insatisfação estudantil, tendo Getúlio à frente, foi como mexer em um vespeiro. Havia anos que quem mandava no Rio Grande do Sul era o presidente (governador) do estado, Antônio Augusto Borges de Medeiros, o líder do borgismo, uma corrente político-partidária da qual Manoel Vargas, pai de Getúlio, era beneficiário. Afonso Pena visitaria o estado com o 
apoio de Borges de Medeiros e de José Gomes Pinheiro Machado, senador da República pelo RS, um dos mais influentes políticos brasileiros da época. Pinheiro Machado, aliás, é um dos protagonistas de um episódio, retratado à página 91 , envolvendo Edmundo Bittencourt, jornalista do poderoso Correio da Manhã, publicado no Rio de Janeiro. Mas há de se ler o livro para descobrir o desfecho tanto da contenda envolvendo o senador e Bittencourt como a gritaria estudantil. Quanto ao Getúlio estudante, uma das fotografias mais impactantes do livro (e que estão organizadas em dois cadernos) o mostra em 1907 (aos 25 anos), durante reunião do Bloco Acadêmico Castilhista, em Porto Alegre, tendo o citado Borges de Medeiros pomposamente à frente dos estudantes.

Outros veículos midiáticos que aparecem com frequência no livro são o Estado de S. Paulo (fundado ainda no século 19) e a Folha da Manhã, predecessora da Folha de S. Paulo. Á página 393, o autor recupera que a Folha da Manhã de 4 de janeiro de 1930 estampou uma reportagem sobre um comício do então candidato presidencial Getúlio Vargas no Rio de Janeiro dois dias antes, apresentando uma visão estereotipada que perseguia o gaúcho de São Borja (cidade fronteiriça à Argentina) desde há muito, no tocante à sua imagem retratada pela mídia nacional. Assim escreveu Lira Neto: “[...] Então aquele era Getúlio Dornelles Vargas, o colosso dos pampas, o grande líder que prometia redimir o país dos males do autoritarismo, da corrupção e da falcatrua política? Aquele, o mais mirradinho do palanque? Um homem, segundo a descrição da Folha da Manhã, 'tão pequenino, tão rechonchudo'?

A característica mostrar um Getúlio rechonchudo era também uma das prediletas da revista $O$ Malho (criada em 1902), conforme se depreende em várias páginas do livro, com as reproduções de imagens da publicação.

Passando-se ainda os olhos por outras páginas do índice remissivo, o interlocutor descobrirá de fato uma enormidade de jornais e revistas utilizados pelo autor. Por volta da página 500, ele conta a passagem de 
Getúlio por Curitiba em plena Revolução de 1930 (outubro daquele ano), quando estava a caminho do Palácio do Catete, em busca de assumir a Presidência do Brasil por meio de um golpe de estado. $\mathrm{Na}$ última das três noites na capital paranaense, Getúlio recebeu cônsules de vários países, entre eles o italiano Amedeo Mammalella, um intelectual que havia participado da mítica Marcha sobre Roma e que já escrevera na revista Ilustração Paranaense que Benito Mussolini (ditador que havia assumido a Itália justamente a partir desta marcha) era um 'gênio multiforme'.

Curiosidades fascistas à parte, há de se destacar o papel essencial que o jornal $A$ Federação teve na publicização das ideias políticas de Getúlio Vargas. A Federação é nominada 53 vezes. Logo na primeira vez em que aparece no livro, o jornal é objeto de linhas sagazes do autor, demonstrando o quão relevante era já nos estertores do século XIX. Lira Neto, à página 37, está tratando de Júlio de Castilhos, político gaúcho ainda hoje alvo de discursos apaixonados (prós ou não), tido como o pai do positivismo no Brasil. Segundo Lira Neto:

Castilhos [...] havia sido o principal redator do jornal A Federação, combativo órgão da propaganda republicana local na chamada fase heroica do movimento. Gago, baixinho, atormentado pelas cicatrizes da varíola que lhe havia devastado o rosto na infância, Castilhos era um orador medíocre, mas um demônio diante de uma folha de papel em branco. Seus artigos, carregados de ironia e furor, fustigavam adversários e arrebatavam leitores.

Manuel Vargas, um dos mais notórios assinantes do periódico, dizia que se tratava do "Alcorão partidário". Júlio de Castilhos morreu prematuramente, em 1903, aos 43 anos, mas seu A Federação sobreviveria até 1937 , quando os partidos políticos foram extintos pelo regime do Estado Novo e, consequentemente, suas publicações. É que A Federação era órgão oficial do Partido Republicano Riograndense (PRR). O fato é que o jornal, ao longo de seus mais de 50 anos de circulação, foi se tornando uma lenda. Ainda em 1886, encartara o 
primeiro guia telefônico de Porto Alegre, informando os nomes dos 72 assinantes. Por volta de 1910, competia de igual para igual com o Correio do Povo (sem vínculo partidário oficial) em número de exemplares no estado. Em 1933, acabou se tornando o Diário Oficial do RS. E assim por diante, embora nada disso se compare a seu papel de agente disseminador dos ideários republicano, castilhista, borgista e, claro, varguista.

Em 1923, por exemplo, logo após o primeiro discurso de Getúlio Vargas como deputado federal, na sede da Biblioteca Nacional (onde funcionava o legislativo brasileiro), A Federação considerou que "à suntuosidade da forma, ele (Getúlio) preferiu a análise demorada e precisa, a argumentação documentada", segundo transcreve o autor na página 200. Muitos anos antes, em 1908, quando Getúlio, então formado em direito e nomeado promotor, retornava à cidade natal, São Borja, A Federação já estava na vida do futuro presidente: "Ilustre moço, caráter talhado para, futuramente, elevar o nome deste já tão glorioso bocado das Missões", estampou o jornal local Uruguay, em 19 de novembro. Detalhe: o Uruguay reproduzia cabalmente o que, em Porto Alegre, publicava A Federação.

Para além destes exemplos citados envolvendo alguns veículos, o livro contém uma enormidade de outras situações. Uma parcela bastante significativa das mais de 1,8 mil notas do livro advém de jornais e revistas. Em alguns dos capítulos (como o 12 e o 13), as menções à mídia são a base dos mesmos, incluindo títulos conhecidos no país todo, como Jornal do Brasil, Revista do Globo e O Globo, até outros nem tanto - Terra Gaúcha e A Esquerda são dois nesta condição.

A prosa de Lira Neto é construída também a partir de outros instrumentos midiáticos importantes, mas nem sempre estudados com afinco, como cartas e telegramas do período. Tais documentos, em geral, estão depositados no arquivo do Centro de Pesquisa e Documentação de História Contemporânea do Brasil (CPDOC) da Fundação Getúlio Vargas (FGV), no Rio de Janeiro. O acervo, claro, é uma preciosidade completa, contendo peças como as diversas 
missivas de Getúlio para Borges de Medeiros ou de Oswaldo Aranha (que se tornaria, nos anos 1940, um diplomata respeitado mundialmente) a Getúlio. Há igualmente que se ressaltar as fotografias e ilustrações reproduzidas no livro, que apresentam desde os estereótipos consagrados (Getúlio a cavalo) até momentos incomuns (como uma fotografia de Getúlio descontraído, já como presidente do país).

Em suas linhas finais, em uma espécie de epílogo, o autor sustenta que sempre esteve inquieto pela ausência de uma biografia de Getúlio que fosse exaustiva (jornalisticamente falando), além de "moderna cuidadosa no trato com as fontes primárias, atenta à abundância de estudos acadêmicos a respeito do período e, em especial, sem o impressionismo da maioria dos relatos biográficojornalísticos já publicados sobre o personagem", conforme escreveu à página 526.

Disse tudo, Lira Neto, tudo, em texto e imagens. 